\title{
Unhealthy Habits of Rural Children in Fayoum Governorate, Egypt
}

\author{
Safaa Khamis Hassan, Wafaa Yousif Abdel Wahed \\ Public Health and Community Medicine Department, Faculty of Medicine, Fayoum University, Fayoum, Egypt
}

Email address:

Safaakh2014@yahoo.com (S. K. Hassan), wafaayousif313@yahoo.com (W. Y. A. Wahed)

\section{To cite this article:}

Safaa Khamis Hassan, Wafaa Yousif Abdel Wahed. Unhealthy Habits of Rural Children in Fayoum Governorate, Egypt. Science Journal of Public Health. Vol. 4, No. 3, 2016, pp. 207-213. doi: 10.11648/j.sjph.20160403.17

Received: April 1, 2016; Accepted: April 11, 2016; Published: May 13, 2016

\begin{abstract}
Background: There is enough evidence that convenient nutrition in childhood is important for healthy development as well as for the prevention of several chronic morbidities later in life. Yet, many children consume diets that are not consistent with dietary guidelines. We aimed to describe unhealthy habits of rural children living in one of the poor governorates in Egypt. Research Methodology: A cross-sectional community based study was conducted among 1049 children aged 6-17 and their parents living in rural area, Beni-Saleh, Fayoum Governorate over a period 10 months. Dietary habits were studied using a food frequency questionnaire. Results: A total of 1049 children in the age of 6 to 17 years were examined for their unhealthy habits. The results revealed that, 35\% of the children were watching TV more than 3 hours many. $90.8 \%$ not doing any type of physical activity on regular basis. $18.3 \%$ were smokers. Only $30.2 \%$ of children take fruits on daily basis with significant different regarding age and sex. $62.9 \%$ were consuming fresh vegetables $3+/$ week. Conclusion: children in rural areas may be at a great risk for malnutrition which affecting their growth and development. The need for healthy lifestyle programming directed to rural people.
\end{abstract}

Keywords: Rural, Nutrition, Dietary, Children

\section{Introduction}

Every day, many times a day, you make food choices that affect your body's health for better or worse. Food choices may benefit or worse your health only a little, but when these choices repeated over years and decades, the consequences become major. Pediatric populations are undergoing the complex processes of growth and development, which are influenced by the genes and illness of the individual in addition to nutritional status [1].

There is enough evidence that convenient nutrition in childhood is important for healthy development as well as for the prevention of several chronic morbidities later in life. Yet, many children consume diets that are not consistent with dietary guidelines [2].

Data worldwide reveals that children have lower than eligible intakes of fruits, vegetables, dairy products and whole grains, but higher than eligible intakes of soft drinks, dessert and fast foods [3-5]. Recognition of children's eating behaviors and the factors that affect such behaviors is a significant stage towards accosting these health interests. Malnutrition can be defined as a condition, in which a deficiency or excess (or imbalance) of energy, protein and other nutrients causes commensurable unfavorable effects on the body (body shape, size, composition), body function and clinical outcome. Malnutrition is one of the most critical global health issues; in developing countries it is assumed that poorness and unawareness are main causative factors of malnutrition [6].

This study aimed to describe unhealthy dietary habits of rural children living in one of the poor governorates in Egypt

\section{Research Methodology}

\subsection{Study Design and Setting}

A cross-sectional community based study was conducted among children aged $6-17$ and their parents living in rural area, Beni-Saleh, Fayoum district, Fayoum Governorate. The village has a population size of about 24.000 Based on the last census Egypt; 2006 distributed in seven residential cubicles. 
Fayoum Governorate's population amounts to 3.07 millions persons [7]. Most of them live in rural communities and work in agriculture and its related industries. The average family size ranges from 4.1 to 4.5 from urban to rural communities respectively [8]. The per capita gross national income for Egypt is US\$ 2,741[9].

\subsection{Study Participants}

All children at the age of 6 to 17 years old were the target groups of our study. Orphan children were excluded. A Cluster random sample technique was selected to include all children in randomly selected three cubicles of total seven cubicles of the selected village. The minimum sample size was determined by using single population proportion formula considering the following assumptions: prevalence of physical inactivity $28 \%, 5 \%$ level of significance, power of study $90 \% 5 \%$ marginal error. Thus the least required sample size was 895 .

\subsection{Data Collection}

Data was collected using predesigned questionnaire by researchers and two nurses through interviewing children and their parents. The data was collected over a period of 10 months from January to October 2015. A pre-designed questionnaire was used to collect data on, age, sex, education and working or not. The father working was meaning work with regular income (official, farmer, seller,..) and not working was manning no regular income that to say from day to day (orzoky). Information related to intake of fruit and vegetables, beverages and non-core foods, such as foods high in sugar, fat and salt. 1) vegetables (whether fresh or cooked) e.g. tomato, spinach, garden rocket (garger), cucumber, molokheya, radish, carrots and others; 2) Fruits e.g. orange, guava, banana, apples, grapes and others; 3) Animal proteins e.g. red meat, poultry (ducks, chicken), fish. 4) Plant proteins e.g. beans (ful and ta'ameyya), lentils, peas 5)milk and dairy products including salted cheese (mesh). 6) Fast foods e.g. hamburger, pizza, 7) sweets such as, cakes, candy, biscuits 8) Carbonated (soft) drinks. life style including Watching TV, practicing any regular exercise. Dietary habits have been studied depending on the questions addressed regarding daily and weekly consumption of common food groups [10].

\subsection{Ethical Consideration}

This study was conducted according to the guidelines laid down for medical research involving human subjects and was approved by Ethics Committee of Faculty of Medicine, Fayoum University, Egypt. A verbal consent was obtained from the parents after they were informed about the study purpose and procedure.

\subsection{Statistical Analysis}

Statistical analyses were performed using the Statistical Package for Social Sciences Version 16. 0 for Windows. Comparison of variables distribution across different categories was done using Chi-square test of significance. A probability value of less than 0.05 was considered statistically significant.

\section{Results}

\subsection{Sociodemographic Characteristics of the Participants}

The total number of the studied population was 1049 child aged from 6 to 17 years with a mean age $13.9 \pm 2.8$. More than half of them were males. $70.8 \%$ of the mothers and $60.6 \%$ of the fathers of the studied children were with unformal education. $45 \%$ of the fathers were with irregular work (orzoki), and most of them with a family size $>5$ persons.

Table 1. Sociodemographic Characteristics of study Participants.

\begin{tabular}{ll}
\hline Characteristics & Number (\%) \\
\hline Age & \\
$6-12$ yeas & $321(30.6)$ \\
$13-17$ years & $728(69.4)$ \\
Mean \pm SD & $13.9 \pm 2.8$ \\
Sex & \\
Males & $613(58.4)$ \\
Females & $436(41.6)$ \\
Mother education & \\
No formal (iliterate \& Read \&write) & $743(70.8)$ \\
Formal (Basic, moderate, High) & $306(29.2)$ \\
Mother work & \\
Yes & $124(11.8)$ \\
No & $925(88.2)$ \\
Father education & \\
No formal (illiterate \&Read \&write & $636(60.6)$ \\
Formal (Basic, moderate, High) & $413(39.4)$ \\
Father work & \\
Yes & $577(55)$ \\
No & $472(45)$ \\
Number of family members & $156(14.9)$ \\
$\geq 5$ & $893(85.1)$ \\
\hline
\end{tabular}

Table 2. Lifestyle characters of study participants.

\begin{tabular}{ll}
\hline Characteristics & NO (\%) \\
\hline Watching TV & $72(6.9)$ \\
No or less than 1hour & $610(58.1)$ \\
$1-2 \mathrm{~h}$ & $367(35)$ \\
More than 3hours & \\
Engagement in physical activity on regular basis & $96(9.2)$ \\
Yes & $953(90.8)$ \\
No & \\
If the parent concerning of the child body image & $207(19.7)$ \\
Yes & $842(80.3)$ \\
No & \\
$*$ Trying to prevent child from eating the empty caloric & \\
food (chips \& crackers, biscuits ...) (431) & $164(38.1)$ \\
Yes & $267(61.9)$ \\
No & \\
Child response of prevention (164)* & $12(7.3)$ \\
Stop eating & $152(92.7)$ \\
Eating more & \\
Presenting the empty caloric food (chips, cake...)as a & \\
\hline
\end{tabular}




\begin{tabular}{ll}
\hline Characteristics & NO (\%) \\
\hline reward for the child $(431)^{*}$ & \\
Yes & $204(47.3)$ \\
No & $227(52.7)$ \\
Eating breakfast regularly & \\
yes & $802(76.5)$ \\
no & $247(23.5)$ \\
Eating while watching TV & \\
Yes & $338(32.2)$ \\
Sometimes & $607(57.9)$ \\
No & $104(9.9)$ \\
Eating outside home & \\
Most meals & $122(11.6)$ \\
Sometimes & $543(51.8)$ \\
No or rare & $384(36.6)$ \\
Smoking & \\
Yes & $192(18.3)$ \\
No & $857(81.7)$ \\
\hline
\end{tabular}

\subsection{Lifestyle Characters of Study Participants}

$35 \%$ of the children were watching TV more than 3 hours many of them were eating while watching TV. $90.8 \%$ not doing any type of physical activity on regular basis. Only $23.5 \%$ skipping breakfast, $47.3 \%$ of the parents presenting empty caloric food as a reward for their children and 80.3 not concerning about the body image of their children.

\subsection{Distribution of Different Food Items Containing Complex Carbohydrates}

Only $30.2 \%$ of children take fruits on daily basis with significant different regarding age and sex. $62.9 \%$ consume fresh vegetables $3+/$ week while most of them (86.2) eat cooked vegetables 1 to 2 times/week. $91.7 \%$ and $13 \%$ of children consume falafel and beans on daily basis, with significant difference regarding age and sex.

*questions directed to children aged from 6-13years

Table 3. Distribution of different food items containing complex carbohydrates.

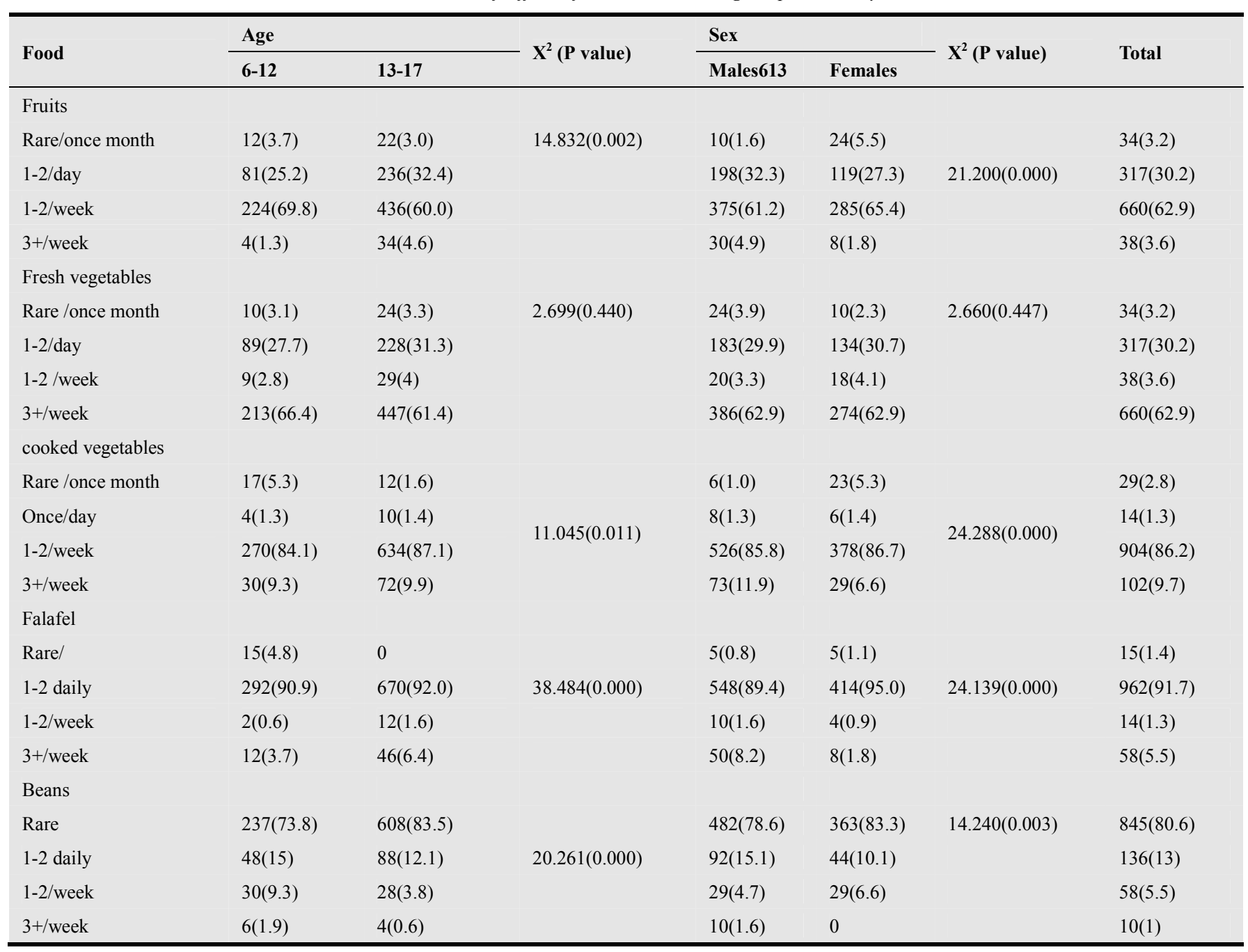

\subsection{Distribution of Different Food Items Containing Animal Protein}

About half of the children consume dairy products on 1-2/day with significant difference regarding age and $80.2 \%$ of them eat poultry $1-2 /$ week. While, $86.6 \%$ and $18.8 \%$ of them eat red meat and fish once/week respectively. 
Table 4. Distribution of different food items containing animal protein

\begin{tabular}{|c|c|c|c|c|c|c|c|}
\hline \multirow{2}{*}{ Animal proteins } & \multicolumn{2}{|l|}{ Age } & \multirow{2}{*}{$\begin{array}{l}X^{2} \\
p \text { value }\end{array}$} & \multicolumn{2}{|l|}{ Sex } & \multirow{2}{*}{$\begin{array}{l}X^{2} \\
\text { P value }\end{array}$} & \multirow{2}{*}{ Total } \\
\hline & $6-12$ & 13-17 & & males & Females & & \\
\hline \multicolumn{8}{|l|}{ Milk\& cheese } \\
\hline $1-2 /$ day & $193(60.1)$ & 284(39) & $40.771(0.000)$ & $267(43.6)$ & $211(48.4)$ & 1.098 & $478(53.2)$ \\
\hline $3+$ day & $28(8.7)$ & $62(8.5)$ & & $58(9.5)$ & $31(7.1)$ & $(0.295)$ & $89(8.6)$ \\
\hline 1-2/week & $100(31.2)$ & $382(52.5)$ & & $288(46.9)$ & $194(44.5)$ & & $482(45.9)$ \\
\hline \multicolumn{8}{|l|}{ Poultry } \\
\hline Rare & $62(19.3)$ & $100(13.7)$ & & $78(12.7)$ & $84(19.2)$ & & $162(15.4)$ \\
\hline 1-2/week & $249(77.6)$ & $592(81.3)$ & $6.580(0.037)$ & $508(82.9)$ & $333(76.4)$ & 8.402 & $841(80.2)$ \\
\hline $3+/$ week & $10(3.1)$ & $36(5.0)$ & & $27(4.4)$ & $19(4.4)$ & $(0.015)$ & $46(4.4)$ \\
\hline \multicolumn{8}{|l|}{ Red meat } \\
\hline Rare/ & $68(21.2)$ & $73(10.0)$ & $23.831(0.000)$ & $75(12.2)$ & $66(15.1)$ & $1.845(0.174)$ & $141(13.4)$ \\
\hline once/week & $253(78.8)$ & $655(90.0)$ & & $538(87.8)$ & $370(84.9)$ & & $908(86.6)$ \\
\hline Fish & & & $0.540(0.462)$ & & & & \\
\hline Rare/ & $265(82.6)$ & $587(80.6)$ & & $479(78.1)$ & $373(85.6)$ & $9.172(0.002)$ & $852(81.2)$ \\
\hline
\end{tabular}

\subsection{Distribution of Different Food Items Containing Excess Salt and Sugar}

$42.0 \%$ of children eat old cheese (mesh) 1 -2times/day and $92.3 \%$ eat peckles $1-2$ times/day with significant difference in relation age and sex. Many of them (69\%), consume chips and crackers 3 and more /day with significant difference in relation age and sex. $67.9 \%$ drinking tea 3 times and more per day immediately after meals. $28.4 \%$ consume juices $1-2$ times $/$ day. Only $12.1 \%$ eat candies and biscuits 1-2times /day most of them were females.

Table 5. Distribution of different food items containing excess salt and sugar

\begin{tabular}{|c|c|c|c|c|c|c|c|}
\hline \multirow{2}{*}{ Food items } & \multicolumn{2}{|l|}{ Age } & \multirow{2}{*}{ X (P value) } & \multicolumn{2}{|l|}{ Sex } & \multirow{2}{*}{$X^{2}$ (P value) } & \multirow{2}{*}{ Total } \\
\hline & 6-12 & 13-17 & & Males & Females & & \\
\hline \multicolumn{8}{|l|}{ (mesh) } \\
\hline Rare/once month & $42(13.1)$ & $66(9.1)$ & & $47(7.7)$ & $61(14.0)$ & 15.844 & $108(10.3)$ \\
\hline 1-2times daily & $163(50.8)$ & $278(38.2)$ & 26.075 & $252(41.1)$ & $190(43.6)$ & $(0.001)$ & $441(42.0)$ \\
\hline $1-2 /$ week & $114(35.5)$ & $368(50.5)$ & $(0.000)$ & $300(48.9)$ & $182(41.7)$ & & $482(45.9)$ \\
\hline 3+/week & $2(0.6)$ & $16(2.2)$ & & $14(2.3)$ & $4(0.9)$ & & $18(1.7)$ \\
\hline \multicolumn{8}{|l|}{ Chips \& cracker } \\
\hline Rare/once month & $2(0.6)$ & $18(2.5)$ & & $18(2.9)$ & $2(0.5)$ & & $20(1.9)$ \\
\hline 1-2 daily & $58(18.1)$ & $70(9.6)$ & 37.603 & $63(10.3)$ & $65(14.9)$ & 33.685 & $128(12.2)$ \\
\hline $3+$ daily & $190(59.2)$ & $534(73.4)$ & $(0.000)$ & $422(68.8)$ & $302(69.3)$ & $(0.000)$ & $724(69)$ \\
\hline 1-2/week & $57(17.6)$ & $98(13.5)$ & & $106(17.3)$ & $49(11.2)$ & & $155(14.8)$ \\
\hline $3+/$ week & $14(4.4)$ & $8(1.1)$ & & $4(0.7)$ & $18(4.1)$ & & $22(2.1)$ \\
\hline \multicolumn{8}{|l|}{ juices } \\
\hline Rare/once month & $11(3.4)$ & $32(4.4)$ & 17.482 & $22(3.6)$ & $21(4.8)$ & & $43(4.1)$ \\
\hline 1-2 daily & $114(35.5)$ & $184(25.3)$ & $(0.002)$ & $142(23.2)$ & $156(35.8)$ & 29.400 & $298(28.4)$ \\
\hline $3+$ daily & $50(15.6)$ & $128(17.6)$ & & $102(16.6)$ & $76(17.4)$ & $(0.000)$ & $178(17)$ \\
\hline $1-2 /$ week & $146(45.5)$ & $384(52.7)$ & & $347(56.6)$ & $183(42.0)$ & & $530(50.5)$ \\
\hline \multicolumn{8}{|l|}{ COLA } \\
\hline Rare/once month & $269(83.8)$ & $638(87.6)$ & & $552(90.0)$ & $355(81.4)$ & & $907(86.5)$ \\
\hline 1-2 daily & $6(1.9)$ & $26(3.6)$ & 16.257 & $12(2.0)$ & $20(4.6)$ & 40.853 & $32(3.1)$ \\
\hline $3+$ daily & $18(5.6)$ & $40(5.5)$ & $(0.003)$ & $34(5.5)$ & $24(5.5)$ & $(0.000)$ & $58(5.5)$ \\
\hline $1-2 /$ week & $28(8.7)$ & $24(3.3)$ & & $15(2.5)$ & $37(8.5)$ & & $52(5.0)$ \\
\hline Tea after meals & & & 61.761 & & & 1.414 & \\
\hline Rare & $27(8.8)$ & $8(1.1)$ & $(0.000)$ & $20(3.3)$ & $15(3.4)$ & $(0.493)$ & $35(3.3)$ \\
\hline 1-2/day & $121(37.7)$ & $285(24.9)$ & & $186(30.3)$ & $116(26.6)$ & & $303(28.8)$ \\
\hline $3+/$ day & $173(53.9)$ & $539(74)$ & & $407(66.4)$ & $305(70)$ & & $712(67.9)$ \\
\hline \multicolumn{8}{|l|}{ Candies \& biscuits } \\
\hline Rare/once month & $175(54.5)$ & 682(93.7) & & $589(96.1)$ & $268(61.5)$ & & $857(81.7)$ \\
\hline 1-2 daily & $105(32.7)$ & $22(3.0)$ & 2.363 & $8(1.3)$ & $119(27.3)$ & 2.101 & $127(12.1)$ \\
\hline 1-2/week & $41(12.8)$ & $24(3.3)$ & $(0.000)$ & $16(2.6)$ & $49(11.2)$ & $(0.000)$ & $65(6.2)$ \\
\hline \multicolumn{8}{|l|}{ Fast food } \\
\hline Rare/once month & $317(98.8)$ & $714(98.1)$ & 0.605 & $603(98.4)$ & $428(98.2)$ & 0.063 & $1031(98.3)$ \\
\hline $1-2 /$ week & $4(1.2)$ & $14(1.9)$ & $(0.437)$ & $10(1.6)$ & $8(1.8)$ & $(0.802)$ & $18(1.7)$ \\
\hline \multicolumn{8}{|l|}{ Peckles } \\
\hline Rare/once month & $8(2.5)$ & $8(1.1)$ & & $7(1.1)$ & $9(2.1)$ & & $16(1.5)$ \\
\hline 1-2 daily & $282(87.8)$ & $686(94.2)$ & 12.759 & $582(.95 .0)$ & $386(88.5)$ & 14.942 & $968(92.3)$ \\
\hline 1-2/week & $31(9.7)$ & $34(4.7)$ & $(0.002)$ & $24(3.9)$ & $41(9.4)$ & $(0.001)$ & $65(6.2)$ \\
\hline
\end{tabular}




\section{Discussion}

Childhood is a dynamic period of growth and development since; children undergo physical, mental, emotional and social changes. Hence the present study was done with the aim to show dietary behavior and nutritional status of children living in rural area in Fayoum governorate the prevalence of poorness is mostly higher in rural area than urban ones, many of poor people live in Upper Egypt, where there are higher rates of illiteracy and deprivation of health services [11]. The present work revealed that $45 \%$ of the fathers of the studied children in this rural area were living without regular work (orzoky), that to say working a day and the other day living without work. Also, the majority of their mothers were not working (table 1), this may have an influence on the food security of rural people.

Factors, such exercise, and physical and motor activity, are affecting growth and development [12]. Physical activity plays a primary role in maintaing health and well-being. Many researchers have been investigated the benefits of exercise. Physical activity profits many parts of the body [13]. Also, educational achievement has been shown to get better and develop with physical activity in children. In relation to duration of physical activity, the United States Department of Health and Human Services in 2008 emitted guidelines for physical activity for children and adolescents. They recommended at least one hour of moderate to vigorous physical activity on a daily basis [14]. In our study, most of the children (90.8\%) not engaged in practicing any kind of exercise like walking, biking, swimming or football on regular basis other than their work activities also, $58.2 \%$ of children were watching TV from $1-2 \mathrm{hr}$ a day and $35 \%$ of children were watching TV more than 3hours /day, 32.2\% eating food while watching TV. Since watching TV is not only a source of fun and sedentary life, but also is a media for advertising of food especially unhealthy food, so watching TV may affect food choices of children. (table2).

In Egypt, data on physical activity among young people showed that $(28.3 \%)$ of young people reported doing no physical activities either for leisure or as part of their daily task and only (28.8\% )of them doing physical activity on regular basis with a very lower incidence of physical activity among females [15]. In a study conducted in Egypt and Saudi Arabia among females adolescent students showed that, less than two thirds $(62.8 \%)$ of Saudi female adolescent students and almost half (48.4\%) of Egyptians paid more than 3 hours per day on sitting activities and almost half of them in both groups did not exercise any physical activity [16]. Also, in a study conducted in a rural area in Saudi Arabia, Abazaid, [17] reported that, $(26 \%)$ of the rural students were watching TV less than one hour per day, $(43.3 \%)$ of them were watching TV from 1 to $3 \mathrm{hrs}$ a day, and about one third of them were watching TV more than 3 hrs a day, while, half of them reported not doing any type of physical activity.

In the present work, $(80.3 \%)$ of the participants were not concerning about the body image (losing or gaining weight) of their children, $(61.9 \%)$ never trying to stop eating chips, crackers even nearly half of them $(47.3 \%)$ presenting empty caloric foods to their children as a reward also, the majority (76.5\%) of the participant were eating breakfast regularly at home or on going to school, on the other hand, $(23.5 \%)$ of them were never eating breakfast (table 2). In a survey conducted on young people in Egypt, they reported that more than half $(57 \%)$ of the participants were having the habit of eating breakfast on daily basis and only, (3.5\%) reported never getting breakfast also they are not concerned about their weight matter. The majority $(75 \%)$ of young females and $(84 \%)$ of young males believed that they had the right weight [15]. In Gaza, they reported that less than thirty (62\%) of adolescents were taking breakfast on daily basis [18].

Consumption of fruits and vegetables plays an animated role in supplying the body with essential nutrients and are associated with decreased risk for chronic diseases and some cancers. The recommendations of average daily intake of fruits and vegetables for the children between ages 6 to 17 years by the American dietary guidelines, 2010 were varied from $1 \frac{1}{2} \mathrm{c}$ cup/day to $2 \frac{1}{2} \mathrm{c} /$ day fruits and $1 \frac{1}{2} \mathrm{c}$ cup to $3 \frac{1}{2} \mathrm{c}$ cup /day of vegetables depending on caloric and physical activity of the child. At least, each meal should contain one fruit or vegetable and serve a variety of fruits and vegetables daily, on the other hand, limiting juice intake [19]. In the present work only, $(30.2 \%)$ of the children eat fruits and fresh vegetables on daily basis and many of them, (86.2\%) eat cooked vegetables 1-2/week (table 3 ), this was more or less similar to a study conducted in Mansoura Egypt, they reported that, the majority $80 \%$ and $29 \%$ of adolescent reported daily vegetables and fruits consumption, respectively [20]. On the other hand, lower rates of fruit consumption were observed in Gaza, where (11.6\%) of boys and $(16.2 \%)$ of girls reported consuming fruits on daily basis (18). Also, in a study conducted in South-western region of Saudi Arabia, revealed that (27\%) of boys and (23\%) of girls never consumed any fresh fruits for a week before the study [21]. This reflects the Low consumption of fruits and vegetables in several regions of the developing countries and is a persistent phenomenon, confirmed by the findings of food consumption surveys [22].

The level of per capita food consumption is one of the measurements of development and welfare of the country, particularly the consumption of so-called "superior goods". Superior goods are those that increase as personal and household incomes grow. Animal protein consumption acts a major portion of such goods [23]. Egypt is an agriculture country and the habit of raising poultry in villages and with plenty of fish in the river and seas, however most of the participant in the study, reported that animal protein consumption just on weekly basis; poultry (80.2\%) 1-2/week, red meat (86.6) once/week and fish (18.8\% ) once/week and this consumption was mostly linked to the marketing day of the village and this was much less than reported by AbdelHady et al [20] they reported that $(25.6 \%)$ of the children 
consume animal proteins (meat, poultry and fish) on daily basis.

Dairy products continue to be an essential dietary source of many micronutrients, including vitamins and minerals such as; calcium, phosphorus, magnesium, zinc, iodine, potassium, vitamin $\mathrm{A}$, vitamin $\mathrm{D}$, vitamin $\mathrm{B}_{12}$, and riboflavin (vitamin $\mathrm{B}_{2}$ ). In addition, dairy products supply children with energy, high-quality protein, and essential and nonessential fatty acids [24] being available in rural areas, and cheaper than other animal sources of proteins, it is reported in our study, that $(53.2 \%)$ of the participants consume milk and homemade cheese (karesh) 1-2 times /day from them $(61.4 \%)$ in the age 6-12 years compared to $(49.6 \%)$ in the age (13-17 years) with significant difference (table 4). However, this was less than, the recommendation for dairy products in the developed countries. They recommended 2-3serving/day in children less than 9 years and 3-5 serving/day in adolescents [25].

High salt intake is associated with several problems such as; high blood pressure, stroke and heart attack in the adult population and there is now evidence to show that a high salt intake in children also influences blood pressure and may predispose an individual to the development of many morbidities; high blood pressure, osteoporosis, respiratory illnesses such as asthma, stomach cancer and obesity-to advice the adult population to decrease their sodium intake will be more working if children do not develop a preference for salt since, liking salt and salty foods is a learned taste preference especially in the early years of life and this can only be made if children are given a diet with little or with no salt at all (26-28). the study showed that, (42.2\%) of the children were consuming old cheese (mesh) 1-2times/day while, (69\%) and (12.2\%) were eating chips and crackers 3 times or more/day and 1-2times/day respectively while, the majority $(92.3 \%)$ consumed peckles 1-2times on daily basis and these was more in males than females and with increasing age (table 5). According to the 2007 Australian National Children's Nutrition and Physical Activity Survey found that children aged 2-16 years are consuming amounts of salt well above the recommended maximum levels. Boys were found to be consuming up to over 9 grams of salt, and girls up to over 6 grams of salt [29]. Many Egyptians have developed the concept of drinking tea right after eating. Tea is very healthy, however, some studies have shown that tea interfere with the absorption of iron [30] in our work about two third of the children consume tea immediately after meals 3times and more and the consumption increasing with age this was similar to $[20,31]$.

\section{Limitation}

The study was done in one rural area so; we cannot generalize the results to all rural and urban communities of our governorate. We didn't take all food groups in our inconsideration; like cereals, we concentrated on unhealthy food items and the probable common deficient foods groups. Also, quantification of total food intake was based on frequency alone we didn't include the portion sizes.

\section{Conclusion}

Results of this research indicate the need for healthy lifestyle programming directed to the parent and their children and may be incorporated in the school curriculum and primary health care programmes. The program should include topics dealing with balancing calorie intake with physical activity; healthy food choices at home, school and in eating out; backing to traditional foods intake which focus more on fruits, vegetables, fat dairy and whole grains

\section{References}

[1] I. A. Maqboo, I. E. Olsen, V. A. Stallings "Clinical Assessment of Nutritional Status" Duggan C, et al. Nutrition in Pediatrics. 4th ed. Hamilton, Ontario, Canada: BC Decker Inc. PP. 5-13. 2008.

[2] National Health and Medical Research Council. Dietary Guidelines for Children and Adolescents in Australia. Canberra: National Health and Medical Research Council, 2003.

[3] A. A. Lake, J. C. Mathers, A. J. Rugg-Gunn, AJ. Adamson. 'Longitudinal chlanges in food habits between adolescence (11-12 years) and adulthood (32 - 33 years) " the ASH30 study. Journal of Public Health, 28(1): 10-16. 2006.

[4] L. Harnack, S. A. Walters, D. R. Jacobs "Dietary intake and food sources of whole grains among US children and adolescents" data from the 1994-1996 Continuing Survey of Food Intakes by Individuals. Journal of the American Dietetic Association.103 (8): 1015-9. 2003.

[5] K. A. Munoz, S. M. Krebs-Smith, R. Ballard-Barbash, "Food intakes of US children and adolescents compared with recommendations". Pediatrics. 100(3 Pt 1): 323-9. 1997.

[6] S. I. Odunayo and A. O. Oyewole "Risk Factors for Malnutrition among Rural Nigerian Children". Asia Pacific Journal of Clinical Nutrition; 15, 491-495. 2006.

[7] Official Fayoum Web Site: http://www.fayoum.gov.eg

[8] CAPMAS. Statistical data and records of El-Fayoum Governorate. Egypt, Central Agency for Public Mobilization and Statistics. 2009.

[9] World DataBank database, 2013. Data refer mostly to the year, selecting all countries, GDP per capita (current US\$), World Bank.,

http://data.worldbank.org/indicator/NY.ADJ.NNTY.PC.CD

[10] World Food Programme. 2010: Hunger. http://www.wfp.org/hunger/faqs

[11] S. El Tawila, M. Gadalla and E. Ali, "Income Poverty and Inequality in Egypt's Poorestvillages". The World Bankand Social Contract Center, Experts' Group Meeting, May 27th, Cairo, Egypt, 2013.

[12] O. Abdel Karim, A. Ammar, H. Chtourou, W. Matthias, S. Lars, P. Anthony, G. Tarek, H. Anita, B. Klaus, "Comparative Study of Physical Fitness among Egyptian and German Children Aged Between 6 and 10 Years" Advances in Physical Education, 5,7-17. 2015. 
[13] Swedish National Institute of Public Health), $2^{\text {nd }}$ edition 2010, chapter 1: Physical Activity in the Prevention and Treatment of Disease http://www.fhi.se/en/Publications/All-publicationsin-english/Physical-Activity-inthe- Prevention-and-Treatmentof-Disease.

[14] Physical Activity Guidelines Advisory Committee: Physical Activity Guidelines Advisory Committee Report Washington, DC: U.S. Department of Health and Human Services, 2008.

[15] Population Council. Survey of young people in Egypt. (SYPE) (2011) Final Report. Population Council. West Asia and North Africa Office January. Available at: www.popcouncil.org/pdfs/2010PGY_SYPEFinalReport.pdf.A ccessed November 15, 2011.

[16] R. El-Sayed, S. El-Hussani, A. El-Gilany, "Health-Related Behaviors of Female Adolescent Students" A Comparative Study Between Egypt and Saudi Arabia Life Science Journal, 10 (4): 1233-1243, 2013.

[17] O. I. Abuzaid, "Eating patterns and physical activity charectristics among urban rural students in Saudi Arabia" University of Nebraska, 2012 Nutrition \& Health Sciences Dissertations \& Theses Digital Commons@University of Nebraska - Lincoln.

[18] A. Abudayya, H. Stigum, Z. Shi, Y. Abed, G. Holmboe Ottesen "Socioeconomic correlates of food habits among school adolescents (12-15 years) in north Gaza Strip". BMC Public Health, 9: 185. 2009.

[19] Dietary Guidelines for Americans, 2010, www.dietaryguidelines.gov

[20] D. Abdel Hady, A. ElGilany, B. Sarraf, "Dietary habits of adolescent students in Mansoura, Egyp" t International Journal of Collaborative Research on Internal Medicine \& Public Health, 6(6): 132-144. 2014.

[21] A. A. Mahfouz, A. S. Shatoor, M. Khan, M. Yetal, A. A. Daffalla, O. M. Mostafa, M. A. Hassanein "Nutrition, physical activity, and gender risks for adolescent obesity in Southwestern Saudi Arabia". Saudi J Gastroenterol. 17(5): 318-22. 2011
[22] WHO. Diet, nutrition and the prevention of chronic diseases. World Health Organ Tech Rep Ser. 2003; 916(i-viii): 1-149.

[23] S. Ibrahim and E. Nafissa, "Animal Protein Food Consumption Patterns \& Consumer Behavior In Egyp" t. Working Paper 9516

[24] M. S. Shils, "Modern Nutrition in Health and Disease" c, 10th ed.; Lipponcott Williams \&Wilkins: Philadelphia, PA, USA. 2006.

[25] D. K. Drorand. H. Allen, "H. Dairy product intake in children and adolescents in developed countries": trends, nutritional contribution, and a review of association with health outcomes Nutrition Reviews journal, 2(72) 68-81. 2014.

[26] A. A. Hazebroek and H. A. Valkenburg, "A randomized trial of sodium intake and blood pressure in newborn infants". Jama. 250(3): 370-3. 1983.

[27] J. M. Geleijnse, A. Hofman, J. C. Witteman, A. A. Hazebroek, H. A. Valkenburg D. E. Grobbee DE, "Long-term effects of neonatal sodium restriction on blood pressur". Hypertension, 29(4): 913-7. 1997.

[28] Scientific Advisory Committee on Nutrition, Salt and health, 2003. The Stationery Office. Available at http://www.sacn.gov.uk/pdfs/sacn_salt_final.pdf. Accessed March 22, 2005.

[29] F. O. Nabag, "Comparative Study of Nutritional Status of Urban and Rural School Girls" Children Khartoum State, Sudan. Journal of Science and Technology, 12, 60-68. 2011

[30] J. George, M. Yiannakis, B. Main, R. Devenish, C. Anderson, R. S. Gibson, "Genetic hemoglobin disorders, infection, and deficiencies of iron and vitamin A determine anemia inyoung Cambodian children”. J Nutr. 142: 781-7. 2012

[31] H. H. Wassef, "Food habits of the Egyptians: newly emerging trends" La Revue de Santé de la Méditerranée orientale, Vol. 10, No 6, 2004. 